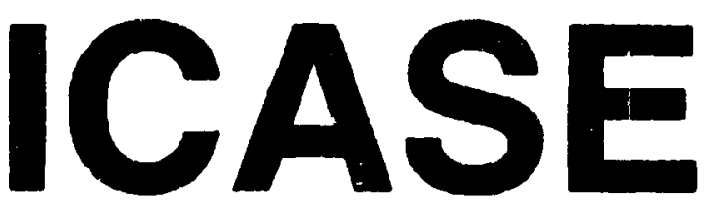

\title{
BALANCING CONTENTION AND SYNCHRONIZATION ON THE INTEL PARAGON
}

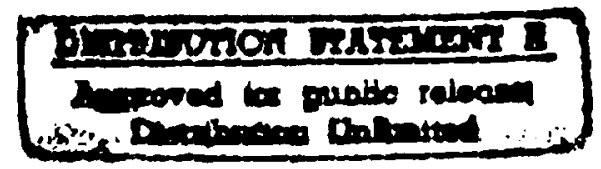

Shrhid H. Bokhari David M. Nicol

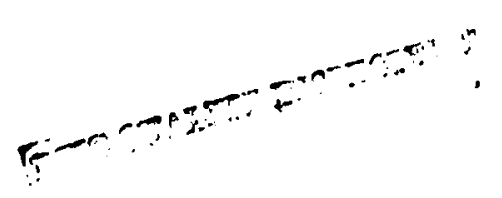

NASA Contract No. NASI-19480

August 1996

Institute for Computer Applications in Science and Engineering NASA Langley Research Center

Hampton, VA 2.3681-0001

Operated by Universities Space Research Association

NASA

National Aeronautics and Space Administration

Langley Research Center

Hampton, Virginia 23681-01001

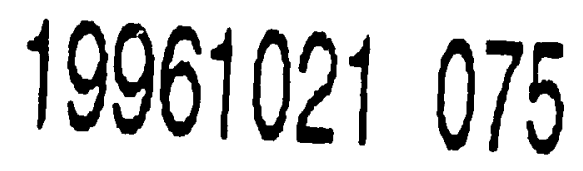




\title{
Balancing Contention and Synchronization
}

\section{on the Intel Paragon}

\author{
Shahid H. Bokhari \\ Department of Electrical Enginetering \\ linive rsity of Enginfering B Technology \\ Lateort. Fakistan
}

\author{
David M. Nicol \\ Departinent of Computer Science \\ Dartmouth College \\ Hanol:er, Nev Hampshire
}

\begin{abstract}
The Intel Paragon is a mesh-connected distributed memory parallel computer. It uses an oblivioue and deterministic message routing algorithm: this permits us to develop highly optimized schedules for frequently needed contmunication patterns.

The complete exchange is one such pattern. Several a pproaches are available for carrying it out on the mesh. We study an algorithm developed by Scott. This algorithm assumes that a cornmunication link can carry one message at a time and that a node can only transmit one message at a time. It requires global synchronization to enforce a schedule of transmissions. Unfortunately global synchronization has substantial overhead on the Paragor. At the same time the powerful interconnection merhanism of this machine permits 2 or 3 messages to share a rommunication link with minor overhead. It can also overlap inultiple message transmission from the same node to some extent.

We develop a generalization of Scott's algorithrn that execute: complete exchange with a prescribed contention. Schedules that incur greater contention require fewer synchronization steps. This permits us to tradeoff contention against synchronization overhead.

We describe the performance of this algotithm and compare it with Scott's original algorithm as well as with a naive algorithm that does not take interconnection structure into account.

The Bounded contention algorithm is always betrer thari Srott's algorithm and ontperforms the naive algorithm for all but the smallest message sizes. The naive algorithm fails to work on meshes larger than $12 \times 12$. These results show that due consideration of processor interconnect and machine performance parameters is necessary to obtain peak performance from the Paragon and its successor mesh machines.
\end{abstract}

Research supported by $N$ ASA (ontract NAS1-19130, whil the g.uthors were in residenre at the Institute for Computar Applications in Science \& Engineering, NASiA langloy Research Center. Harnpron. Virginia.

This rearitch was performed using the Trex 512 node Paragon ciperated by Cialtech on bethalf of the Concurrent Supercomputing Concortiun. Access on this farlity was provided by VASA

Shahul H. Bokhari was additionally supported by a grant from the Directorate of Rcsearch Extension and Advirnry Services. Iniversity of Engineering 8 . Jechnology, Lathore. 


\section{Introduction}

Interprocessor communication overhead is a major factor that limits the performance of distributed memory purallel computer systems. All machines, no matter how powerful their interprocessor communication mechanism. suffer from this overhead. Communication overhead is exacerbated by node and link conten'ion. Node contention arises when a node at tempts to transmit or receive several messages simultaneously. link contention is caused by the sharing of a cornmunication link by two or more messages. Contention arises in all but the simplest communication requirements. In some cases. contention can be minimized or eliminated by careful scheduling of messages. However this requires that all processors in the system synchronize themselves at specific point:s in time-thereby incurring synchronization overhead.

The parallel algorithm designer is thus faced with the following dilemma:

- A completely contention-free schedule will incur substantial synchronization overkead.

- A completely synchronization-free schedule will result in heay contention overhead.

Clearly there is a need to find a balance between the two types of overhead in order to minimize the overall execution time of the parallel algorithm.

The complete exchange is an interprocessor communication pattern that arises in a number of important applications. It. requires each processor to send a distinct message to every ot her processor in the systen and is thus the heaviest communication requirement that can be imposed on a parallel compuler. ('omplete exchange has be'cn cxtensively studied and a number of algorithms are known for it a fficient execution on various interconnection net works.

We describe a atudy of the complete exchange on mesh connected parallel machines. We start with an algorithm to execute the complete exchange on meshes that was developed by David Srott. We develop a generalization of this algorithm that permits us to decrease synchronization overhead by increasing contention. We describie our experiments with this approach on the 512 node Intel Paragon inesh at Calterh. It is seen that the generalized algorithm cars be used to balance contention and syruchronization overhead and thus obrain significant reduction in the time required 10 execute the compleif exchange. The generalized algorithm is also shown to give better performance than a naive algorithm that does not take the interconnect of the Paragon into account.

Our results dernonstrate that careful consicleration of parallel machine interconnect and performance chararteristics is needed in order to obtain the best perforunance. As an extrcme example. the naive algorithm (which does not take the interconnect into account) fails to execute on Paragon meshes of size jarger than $12 \times 12$. becausc the operating, system cannot allocate enough memory for the large amount of communication traffic required. For such meshes we have no choice but io use an 


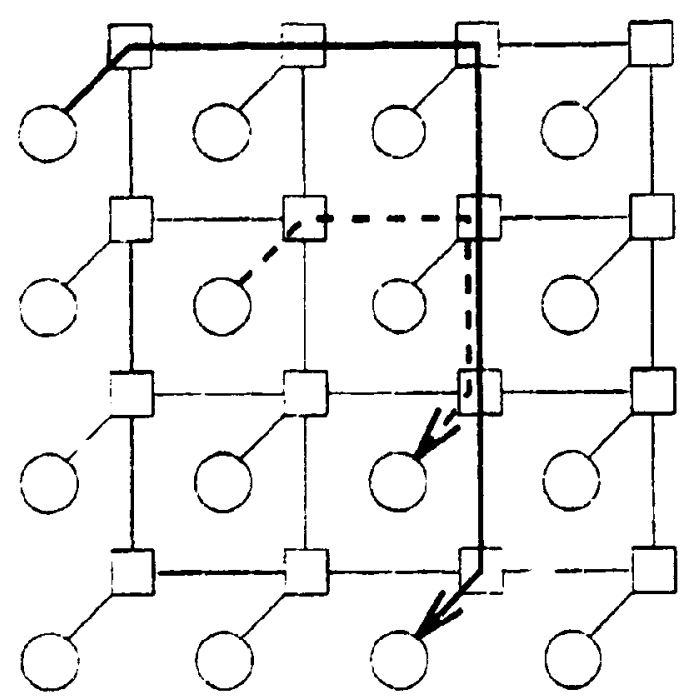

Figure 1: The mesh interconnert of a $4 \times 4$ Paragon. The circles represent compule nodes while the squares show special purpose hardware for communication. Message routing is done via the "row column" algorithrn explained in the text. The figure shows two pairs of processors communicating and contending for a ingle edge. Such link rontention can lead to substantial overhead.

algorithm that carefully schodules communications, such as Scott's algorithm or its generalization (described in this paper).

\section{The Paragon Mesh}

The mesh has long been a popular choice for interconrecting parallel computers. Currently. the most powerful example of the mesh is the Intel Paragon'. The specific machine on which the experiments described in this paper were carrice out is bocated at the Cienter for Advanced Compuling Research at Caltech ${ }^{2}$. It is made up of 512 compute nodes organized in a $1.6 \times 32$ array. Each node is composed of two Intel $\mathrm{i} \$ 60 \mathrm{0}$ processors. Onc serves as a compuie processor and the other as a communication processor. In addition there is special hardware for interfacing with the intercommunication network. The interprocessor communication network is a mesh with "row-column" routing (Figure 1). A message liaveling from source s to destination $t$ frst travels along the tow in which $s$ lies. until it reaches inc column in which $t$ lies; it then travels along the column to $t$. Two messages traveling si. multancously bet ween two differen: source-dectination pairs mny need to traverse the sane communication link, as illusitrated in Figure 1, and will incur link contentium

\footnotetext{
'htep://wwe sed. intel. con/paragon.beml

${ }^{2}$ http: //ugr,cacr, caltech, edu
} 


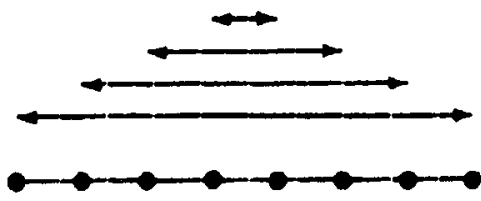

Node $:$ ont $=1$. Link cont $=: 4$

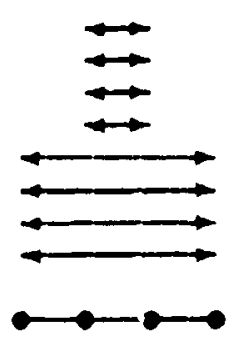

Node cont $=4$. link cont $=8$

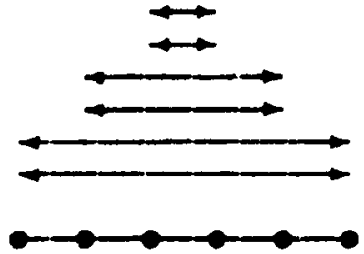

Node $\operatorname{con} t=2$, Link $\operatorname{con} t=6$

Figure 2: Explanation of node and link contention on chains of processors. Node contention equals the number of messages that a processor attem pts to transmit simultaneously. Link contention is given by the maxinum number of messages passing through any communication link in the chain.

overhead.

The routing mechanism on the Paragon is oblitious (the paths betwetis all sourcedestination pairs are statically defined) and deterministic (a single route exists between every source-destination pair). As a result. it is possible to arcurately predict the time required for a communication step. provided no contention is taking place.

A message passing through a. node: en route to its destination does not impact the computation occuring at that, node as the routing is carried out by special hardware. The i860s run at $50 \mathrm{MHz}$ and are capable of 75 MHlops. This machine has 32 Megabytes of memory per node of which about 24 Megabytes are arailable for user programs. Measured performance parameters of the Paragon are given in Table 1. The communicition expression in this table is obtained by using the specific com. munication scheme: employed in subsequent experiments with the complete exchange. and thus differs from the expiessions reported elsewhere $[2.5]$.

Table 1: Performance Parameters for the Paragon

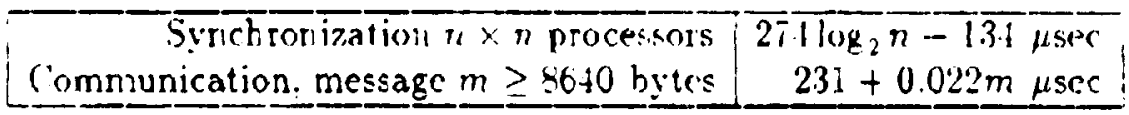

I'igure 2 clarifies the concepts of node and link contention. as applied to dhains of processors. The inlerpretation of these concept: for meshes is very similar though difficult to explain in a simple diagram.

The successor machine to the Pasagon is the Intel ASCI (Acrelerced Strategic Computing Initiative) Teraflop ${ }^{3}[12]$. Which is currently being, installed at Sandia Laburatories. This mach:ne also lats a mesh interconnert and the terhnigues de.

\footnotetext{
3bttp://ont.sed, intel, com/t1lop, hts.l

ihtep://000.cs.andia gor/terullop.htal
} 


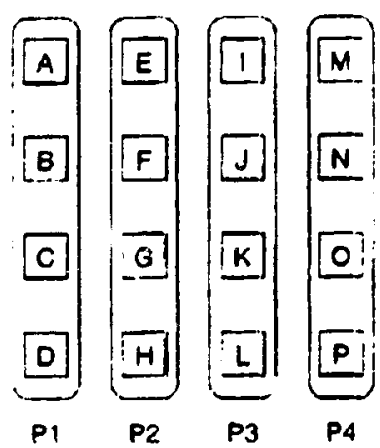

(a)

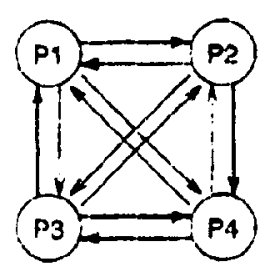

(b)

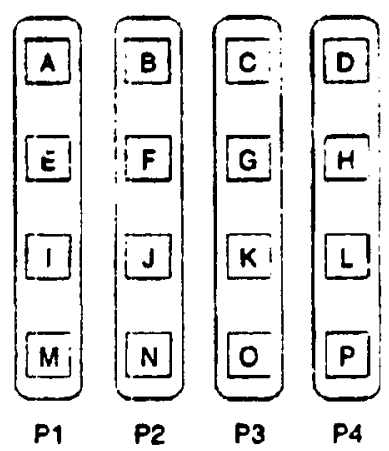

(c)

Figure 3: Complete Exchange on 4 Processcrs. To change storage from column order (a) to row ordf $i(c)$. each processor must send a distinct message to every other processor (b).

scribed in this paper should be applicable to the new machine as well.

\section{The Complete Exchange}

un wistributed menory parallel computer. the complete txchangt requires: each of $N$ processors to send a distinct $m$ byte block to each of the remaining $N-1$ processors. This comrnunication pattern. which is also known as all-to-all personalized is at the heart of many important rnulicomputer algorithms such as matrix transposition. matrix-vectur multiply. Fast Fouricr Transforms and the Alternating Directions Implicit (.1D) method for solving partial differential equations. To understand the data movement required by this pattern refer to Figure 3 which shows a $4 \times 4$ block matrix stored on 1 processcrs. In part (a) of this Figure the matrix is stored in column order. In part (c) the layout bis been changed to row order. It is clear that to change from (a) to (c), each processor must transmit a block of data to every other processor. This is shown in part (b) which is a complete directed graph of four rodes.

In general. complete exchange on $N$ processors can be represented by a complete directed graph of $P$ nocles. It is thus the densest possible communication requirement and the time required by a distributed menory multicomputer to execute it is an important performance parameter. At the same time. it is a challeuge for the algorithm designer to develop good algorithms for complete exchange on different parallel architectures.

A number of algorithms have hecn developed for executing the complete exchange on hyperculies $[4.6 .7 .8 .11]$ and meshes 1,9$]$ These algorithms altempt to obtitin high performance by carefully scheduling communications so as to avoid node and limk contention. We can classify these algorithms into two rategories. In Derect algoritlms: each block is transmitted once to its ultimate destination: in store-and- 
forward algorithms a block is combined with others and transmitted in stages via intermediate processors. Store-and-forward algorithms [i] strive to reduce the impact of startup time by incurring data permutation and extra transmission overbead. It has been shown that such algorithms perform well foi small message sizes. Direct algorithms [11.9], on the other hand, have better performance for large message sizes.

The time required to execute the complete exchange will depend on the iriterconnection network and the schiedule of data transfers. We shall address the problem of developing good direct algorithms for mesh connected parallel architectures. The sparsity of the mesh interconnect makes this a difticult endeavor. This is in contrast with hypercubes, for which optimal direct algorithms (i.e.. those that require $\lambda^{r}-1$ transmissions for an $\lambda$ processor system) have been known for some time.

\section{Scott's Algorithm}

The problem of implementing complete exchange on a mesh architecture has been studied by Scott [9] under. the following assumptions:

- A node can send and receive at most one message at a time.

- A cornmunication link can carry at most one message in cach direction at one time.

- Message's are routed according to the "rcw-column" algorithm, that is, a message frorn processor $x_{1}, y_{1}$ to processor $x_{2}, y_{2}$ first travels along a row: to $x_{2}, y_{1}$ and ther along a column to $x_{2}, y_{2}$.

Scott show's that. under these assumptions. a square mesh of 1 nodec cannot ac.rieve the complete exchange in fewer than $\lambda^{3 / 2} / 1$ steps, unlike a hypers sbe: which requires $\lambda-1$ steps. The intuitive reason for this is the far richer interconnection of the hypercube which comcs, of course: at the cost of a logarithmically increasing node degree.

Scott goes on to describe a procedure that will generate a schedule of transmissions that takes exartly $\lambda^{3 / 2} / 4$ steps. for the case where $\lambda$ is a mulliple of 4 . This procedure is based on cornposing or "cross-multiplying" pairs of 1-dimensional pernutations and can lead to many different sets of schedules, depending on the choices made when composing the permutations. Figure 1 show three permutations out of a set of 128 generated for an $8 \times 8$ mesh. The cells in this diagram are assumed to be numbered in row-major order. A non-blank cell indicates the coordinates of the target to which the corresponding processor has to transmit. A blank cell indicates that the corresponding processor docs not transmit anything during that permutation. As we increase the size of the mesh. the proportion of these idle processors increases becalse the mesh interconnet cannot support transmissions by all processors. It is thesc idle processors that lead to the superlincar $.^{3 / s} / 4$ expression for run tine. 


\begin{tabular}{|l|l|l|l|l|l|l|l|}
\hline & & 1,4 & 1,2 & 1,5 & 1,3 & & \\
\hline & & 7,4 & 7,2 & 7,5 & 7,3 & & \\
\hline 3,6 & 3,0 & & & & & 3,7 & 3,1 \\
\hline 5,6 & 5,0 & & & & & 5,7 & 5,1 \\
\hline 2,6 & 2,0 & & & & & 2,7 & 2,1 \\
\hline 4,6 & 4,0 & & & & & 4,7 & 4,1 \\
\hline & & 0,4 & 0,2 & 0,5 & 0,3 & & \\
\hline
\end{tabular}

\begin{tabular}{|c|c|c|c|c|c|c|c|}
\hline 2,1 & 2,7 & & & & & 2,0 & 2,6 \\
\hline & & 4,3 & 4,5 & 4,2 & 4,4 & & \\
\hline \multirow[t]{3}{*}{7,1} & 7,7 & & & & & 7,0 & 7,6 \\
\hline & & 1,3 & 1,5 & 1,2 & 1,4 & & \\
\hline & & 6,3 & 6,5 & 6,2 & 6,4 & & \\
\hline \multirow[t]{2}{*}{0,1} & 0,7 & & & & & 0,0 & 0,6 \\
\hline & & 3,3 & 3,5 & 3,2 & 3,4 & & \\
\hline 5,1 & 5,7 & & & & & 5,0 & 5,6 \\
\hline
\end{tabular}

\begin{tabular}{|l|l|l|l|l|l|l|l|}
\hline 3,5 & & 3,0 & & & 3,7 & & 3,2 \\
\hline & 2,3 & & 2,6 & 2,1 & & 2,4 & \\
\hline & 6,3 & & 6,6 & 6,1 & & 6,4 & \\
\hline 0,5 & & 7,0 & & & 7,7 & & 7,2 \\
\hline & & 0,0 & & & 0,7 & & 0,2 \\
\hline & 1,3 & & 1,6 & 1,1 & & 1,4 & \\
\hline & 5,3 & & 5,6 & 5,1 & & 5,4 & \\
\hline 4,5 & & 4,0 & & & 4,7 & & 4,2 \\
\hline
\end{tabular}

Figure 4: Three ont of a set of 128 permutations for an $\times 8$ mesh. The cells in this figure represent processors and are numbered in row-major urder. Al enpty cell indicates an inactive processor. $A$ non-empty cell gives the coordinates of the cell to which that cell transmits. 


\section{Bounded Contention Algorithm}

The permutations generated by Scott's procedure assume that only one message can travel over a link in one direction at a time. As a result all nodes cannot, in general, transmit during any given step. This is evident. in Figure 4. where we see that half the nodes are alway's inactive. If we have a square mesh of $n \times n=N$ nodes, the number of steps required is $n^{3} / 4=: N^{3 / 2} / 4$ and during each step a fraction $4 / n$ of the nodes is inactive.

If we relax the constraint that a link only carry one message at a time, it becomes int ere ting to explore if schedules can be generated in which contention is bounded by some integer $c$. The permutations shown in Figure $\&$ cannot simply be superimposed because the active nodes in any pair of permutations are not disjoint.

Scolt's generation technique creates permutations that can be executed in any order to achieve the complete exchange. The set of permutations generated is not unique. We bave developed an algorithm to generate a set of permutations in a special collapsible order. This generates permutations in such a way that consecutive entries in the sequence can be collapsed to form a denser permutation (i.e., one in which more nodes are active), with greater contention. The collapsibility property is not true of Scott's permulations in general.

Figure 3 shows two permutations for an $8 \times \&$ mesh that can be collapsed to form a third. Since each of the constituent permutations has link contention bounded by 1. the contention in the collapsed permutation is bounded by 2. It is also clear that each node is transmitting exactly once.

For the $8 \times 8$ mesh shown in Figure 5 . the fraction of active nodes in the constituent permutations is $4 / n=1 / 2$. We can combine set $s$ of two permutations each and thus halve the number of steps required to achievc completc exchange.

We have developed a theory of collapsible schedules for the complete exchange on meshes. We can show that for a square mesh of $n \times n=N$ nodes that permits contention $c$ on its links, the number of steps required is $x^{3} / 4 c$. where $c$ is an integer $\leq n / 4$ and $c$ divides $n / 4$ (j.e.. $n / 4 c$ is an integer).

We have irnplemented an algorithm based on this theory and used it to generate and verify shedules for meshes of size $4 \times 4.8 \times 8, \ldots, 32 \times 32^{5}$. Table 2 shows the impravement possible as the permitted contention is allowed to increase. For each mesh size. the minimum steps possible are $n^{2}$ at $r=n / 4$. This is within 1 of the theoretical minimum $n^{2}-1$. The blank entrics beluw the principal diagonal in Table 2 are caused by the constraint that $n / t c$ be an mineger. This table assumes that no norle contention is permitted. i.c. a node cannot transmit more than one message at a time.

The schedules generated by this algorithm have the interesting property that they can be oollapsed to whatever degree is permitted by the rulcs stated above. Thus the schedule for $16 \times 16$ meshes could be collapsed for lirk contention 2 or + by combining

SScheduler for mashes of size $1 \times 1,8 \times k, 12,12$ and 16,16 are available at the following aile $1: p: / / 1$ tp. Icase. adu/pub/cs/shalidd 


\begin{tabular}{|l|l|l|l|l|l|l|l|}
\hline 1,1 & 1,7 & & & & & 1,0 & 1,6 \\
\hline 7,1 & 7,7 & & & & & 7,0 & 7,6 \\
\hline & & 3,3 & 3,5 & 3,2 & 3,4 & & \\
\hline & & 5,3 & 5,5 & 5,2 & 5,4 & & \\
\hline & & 2,3 & 2,5 & 2,2 & 2,4 & & \\
\hline & & 4,3 & 4,5 & 4,2 & 4,4 & & \\
\hline 0,1 & 0,7 & & & & & 0,0 & 0,6 \\
\hline 6,1 & 6,7 & & & & & 6,0 & 6,6 \\
\hline
\end{tabular}

\begin{tabular}{|l|l|l|l|l|l|l|l|}
\hline & & 1,3 & 1,5 & 1,2 & 1,4 & & \\
\hline & & 7,3 & 7,5 & 7,2 & 7,4 & & \\
\hline 3,1 & 3,7 & & & & & 3,0 & 3,6 \\
\hline 5,1 & 5,7 & & & & & 5,0 & 5,6 \\
\hline 2,1 & 2,7 & & & & & 2,0 & 2,6 \\
\hline 4,1 & 4,7 & & & & & 4,0 & 4,6 \\
\hline & & 0,3 & 0,5 & 0,2 & 0,4 & & $\vdots$ \\
\hline & 6,3 & 6,5 & 6,2 & 6,4 & \\
\hline
\end{tabular}

\begin{tabular}{|l|l|l|l|l|l|l|l|}
\hline 1,1 & 1,7 & 1,3 & 1,5 & 1,2 & 1,4 & 1,0 & 1,6 \\
\hline 7,1 & 7,7 & 7,3 & 7,5 & 7,2 & 7,4 & 7,0 & 7,6 \\
\hline 3,1 & 3,7 & 3,3 & 3,5 & 3,2 & 3,4 & 3,0 & 3,6 \\
\hline 5,1 & 5,7 & 5,3 & 5,5 & 5,2 & 5,4 & 5,0 & 5,6 \\
\hline 2,1 & 2,7 & 2,3 & 2,5 & 2,2 & 2,4 & 2,0 & 2,6 \\
\hline 4,1 & 4,7 & 4,3 & 4,5 & 4,2 & 4,4 & 4,0 & 4,6 \\
\hline 0,1 & 0,7 & 0,3 & 0,5 & 0,2 & 0,4 & 0,0 & 0,6 \\
\hline 6,1 & 6,7 & 6,3 & 6,5 & 6,2 & 6,4 & 6,0 & 6,6 \\
\hline
\end{tabular}

Figure .5: The first two pormutations call be collapsed to form the third. This is possible because the active colls in the first permutation correspond exactly to the inactive cells in the second and rice tersa. Since the link contention in the first two permutations is 1 . the combined permutation has link contention 2. 
Table 2: Steps required as contention is allowed to increase.

\begin{tabular}{|c|c|c|c|c|c|c|c|c|}
\hline \multirow{2}{*}{$\begin{array}{c}\text { Jesh size } \\
(n \times n)\end{array}$} & \multicolumn{8}{|c|}{ Permitted link Contention $(c)$} \\
\hline & 1 & $\overline{2}$ & 3 & 4 & 5 & 6 & 7 & $\bar{\pi}$ \\
\hline $4 \times 4$ & 16 & & & & & & & \\
\hline $8 \times 8$ & 128 & 64 & & & & & & \\
\hline $12 \times 12$ & $43 \overline{2}$ & & 144 & & & & & \\
\hline $16 \times 16$ & 1024 & 512 & & 256 & & & & \\
\hline $20 \times \overline{20}$ & $\overline{2000}$ & 1000 & & & 400 & & & \\
\hline $24 \times \overline{24}$ & $34 \overline{56}$ & 1728 & 1152 & & & 576 & & \\
\hline $28 \times 28$ & .5488 & & & & & & 784 & \\
\hline $32 \times \overline{32}$ & $\overline{81} \overline{92}$ & 4096 & & 20.18 & & & & 1024 \\
\hline
\end{tabular}

ronsecutive sub-sequences of 2 or 4 permutations as shown in Figure 6 . If the first synchronization in part (c) of this figure were removed we would have a schedule with node as well as link contention. Two nodes would be attempting to transmit at a time while the link conterition would be doubled from 4 to $\&$. This can lead to further improvements in run time. as described bclow.

\section{Implementation Considerations}

The rux message passing library was used for our experiments on the Paragon. This library has its origins in the Intel iPSC .860 hypercube which has tuo types of messages: FORCED and UNFORCED. FORCED messages are transmitted from source to destination under: the assumption that a receive has already been posted (i.e.. buffer space for reception has been specified! at the clestination. If an arriving message does not fi.d a receive posted, it is discarded. UNFORCED messages do not require a reccive to be posted beforehand. Before an UNFORCED message is transmitted there is an exchange of control messages between source and dest inaticin to allocate cperating systcm buffer space for the message. This leads to additional overhsad in communication (because of the control messages). extra memory requirements, and the penalty of copving from operating system buffers to user areas [3]. Further details of the communication overhead on the Paragon appear in [2]. Shirley et al. [10] discuss how operating system timer in mrrupts complicate performance measurement and prediction on this inarhint.

On the Paragon, FORCED and UNFORCED messages are supposed 10 perform identically. It has been our experience that operating system space is allocated for all possible arriving messages in addition to any user meniory locations that may be sel aside by explicitly posted receives. The user ran eperify the amonnt of memory buffers that the uperat ing system is to set aside for this purpose. Despite this, when large numbers of large-sized messages are expected. the coperaling sy stem call rum 
(a)
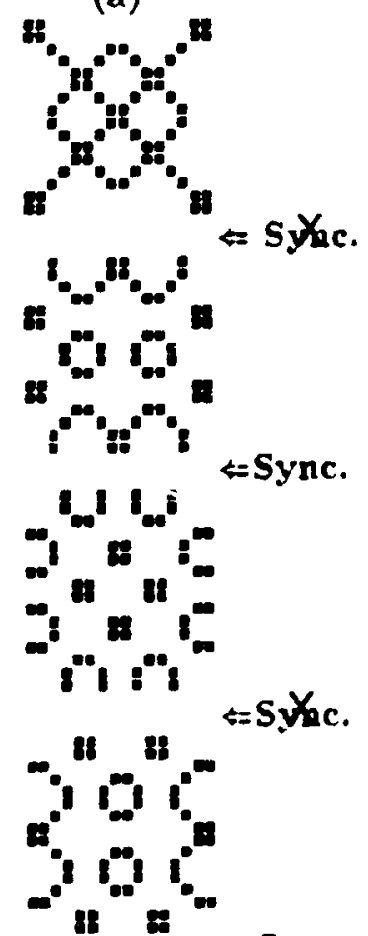

(1) Sync.

Sync.

(18)

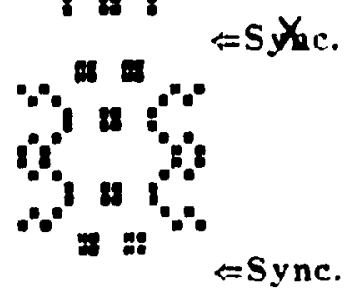

(b)

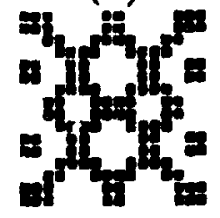

FSy.z.
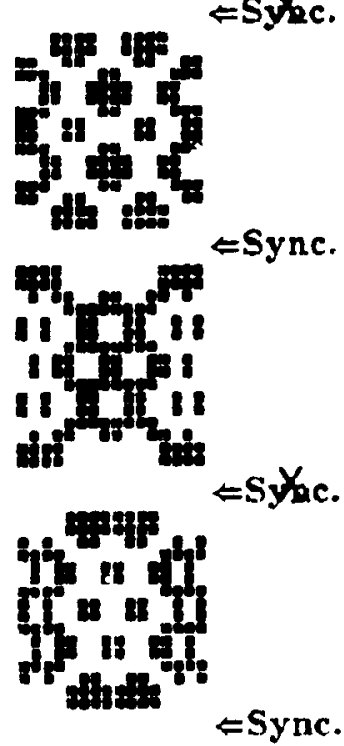

(c)

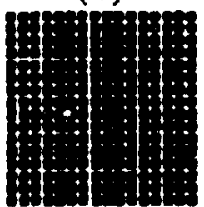

ESyne.

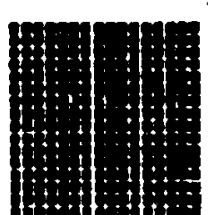

६Sync.

Figure 6: a) The first 8 (of 1024 ) members of a collapsible schedule for a $16 \times 16$ mesh. Active nodes are indicated by square blocks. When islternate synchronizations are removed (X). pairs of a uccessive permutations collapse as shown ill part (b) giving a schedulo with maximum link contention?. Repeating this proress ;esults in a schedule with link contrntion 1 (c). Further removal of syuchronization steps res:lts in increasing node contention. 
out of resources thereby causing the machine to hang. Needless to say, FORCED messages should only be used if conmunication requirements are well understood and receives can be posted before any messages are launched. Deadlocks can develop if this requirement is not satisfied.

The Bounded contention complete exchange algorithm that we have developed has a completely determined comrnunication requirement and we could thus use FORCED messages. To compare the performance of the Bounded contention algorithm against an algorithm that does not take the topology of the mesh into account, we implemented a naive algorithm wo carry out the complete exchange. This algorithm simply transmits blocks of data from each processor to the remaining processors without regard for link or node contention. We were unable to get the naive algorithm to function reliably beyond $12 \times 12$ processors because: the large numbers of outstanding receives required could not be accommodated by the operating system.

Each node of the Paragon has an i860 processor dedicated to in erproressor communication. This processor takes over a considerable portion of the overhead of starting, a data transfer. We have found that asynchronous receives and sends yicld much better performance because the compute processor can spawn a task on the cominunication processor and carry on with its work without having to wait for the uperation to complete. This, in fact. is how the machine manages to perform well under node contention.

Memory access and thus data communication on the Paragon is heavily affected by the starting address of a transfer. In our experiments we have aligned all arrays to 4 li boundaries (the page size of the machine) to minimize this impact.

\section{Experimental Results}

When implemerting Bounded contention completc cxchange on the Paragon. several aspects of the machine performance iad to be taken into account.

1. The amount of contention in a schedule can only be controlled by global synchronization. The o: shead of this operation is substantial (Table 1).

2. While the machine can tolerate node and link contention, there is non-zcro overhead assoriated with surh contention.

3. Overincads for node and link contention ate hearily dependent on the type of communicatim being carried out. It is very difficult to obtain simple cxpressions for thene orerheads. For example. measmrements taken of the 1-dinemsional communication pattorns in Figure 2 do not apply to 2-dimensional communicaltions.

The above a pects roupled with the use of vintual menory on the machine and the complex efferts of operating siystem interrugts [10] make it extramely difficult in predict the communication performanre of this machinc under varying amounts of 


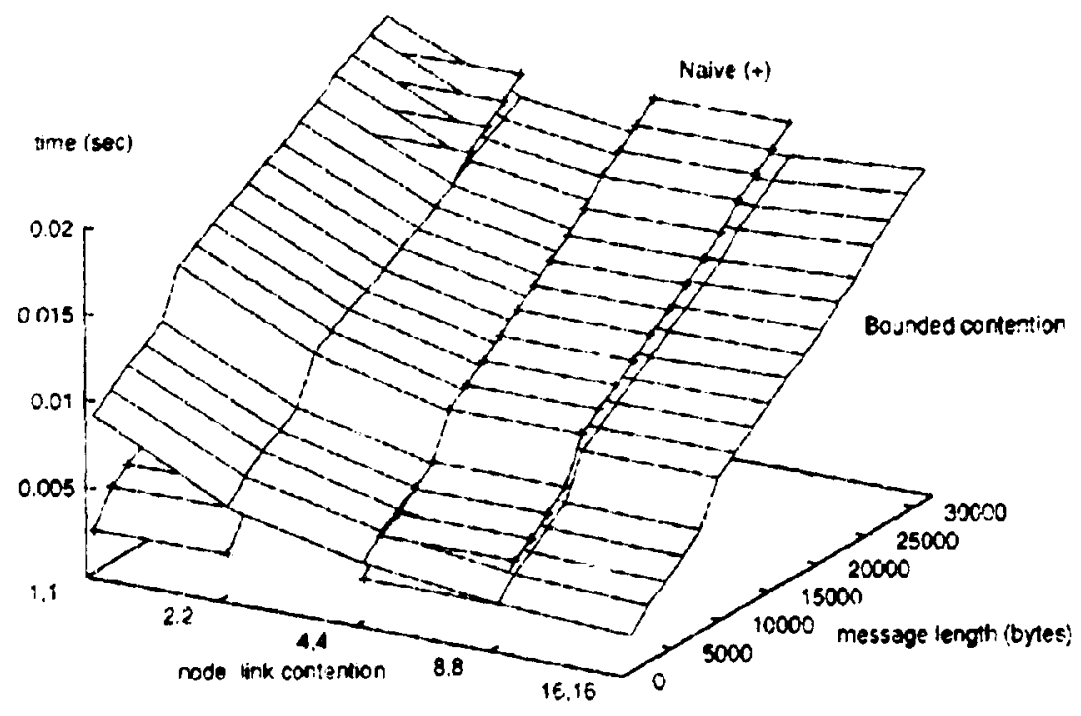

Figure 7 : Waive aigorithm (" $+"$ ) compared wilh Bovgded contention algorithm on a $4 \times 1$ Yaragon. The najve algosithm run times, which do not vary with contention, haie been shown as a series of sirips for clarity.

rode and link contention. This in turn also makes decision of the level of rontention to bic used difficult.

Our approach is to evaluate the algorithm for various levels of permitted contention and empirically decide on the best level for a given mesh size. This is rasily. done once a collapsible sequence has been generated for a mesh: simply insert barrier synchronizations in the sequence. modulo the permitied contention. Thus. for a $32 \times 32$ mesh we would insert barriers after every 1.2 , 4 or 5 permutations. For example. insertiug barriers after cvery 4 permut ations c auses each group of 4 to collapse into one permutation with contention 4.

Figures $i, 8,9$ and 10 compare the jerformance of the naive and Bounded rontention algorithms on neshes of size $1 \times 1.8 \times 5.12 \times 12$ and $16 \times 16$ respectively. for varying amounts of contention and message sizes. The $x$-axes of these plots are labeled with the pairs (node contention. link contention i, as clarified in figure 2 . The performance of the raive algorithn. which does not wary with contention. is shown as a series of strips so that the surface of the Bounded algorithm can be seen clearly:

The small size of the $4 \times 4$ mosh dores not rermit a collarsible schcelule to be gencrated (see Table 2). Despite this there is in improvement in performance as contention increases. because the number of anchronization steps required is reduced. Furthermore. node contention also results in slight decreases in ime as launching two or more inesagges in quick succession permits the utilization of intranode parallolism due i a separate communication processor.

cures 8 and 9 show much more interesting results obtained from experiments on $\bar{x} x$ and 12,12 meshes. Here. the performance of the Bounded algorithm 


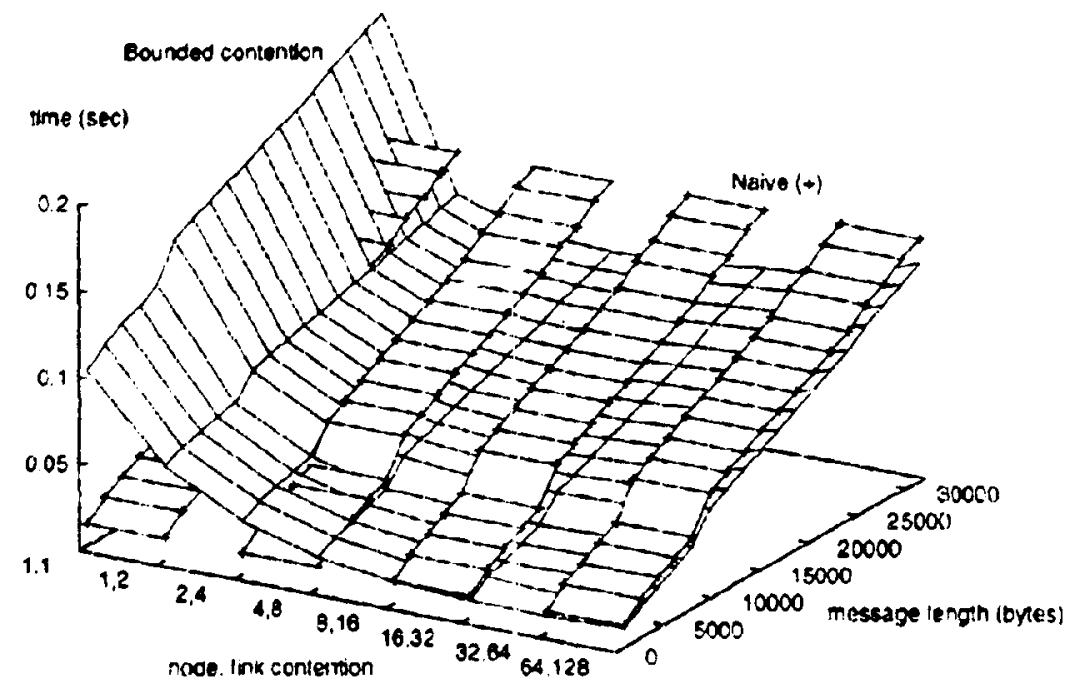

Figure 8 : Cornparison of the $t w n$ algorithms on an $8 \times 8$ yaragon.

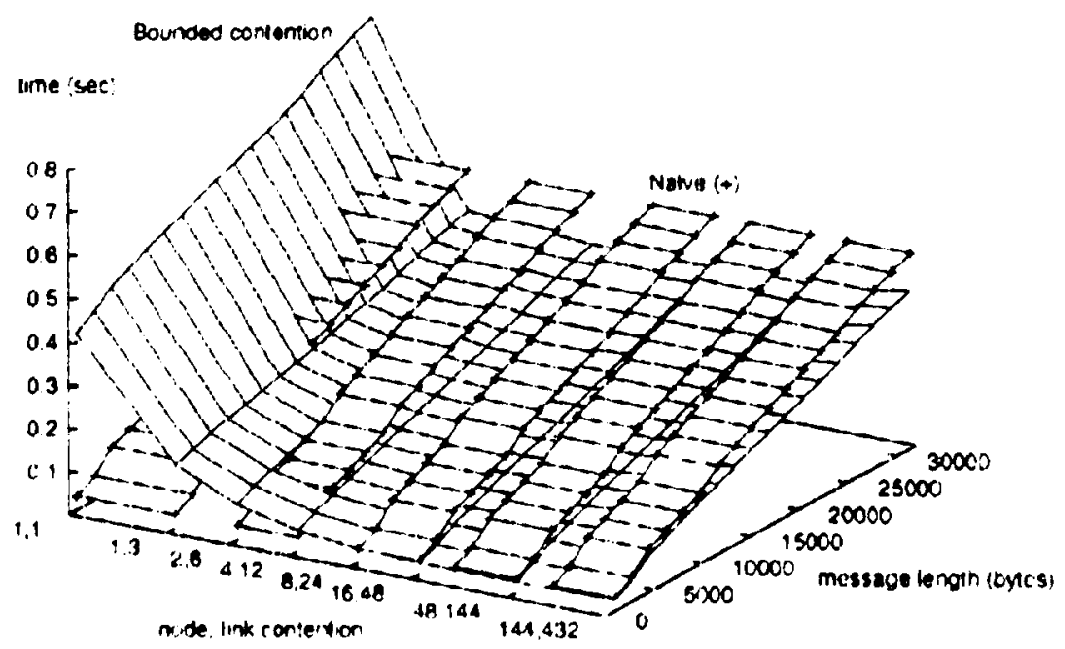

Higure 9: rompariorm of tile two algorithms on a $12 \times 12$ Paragon. 


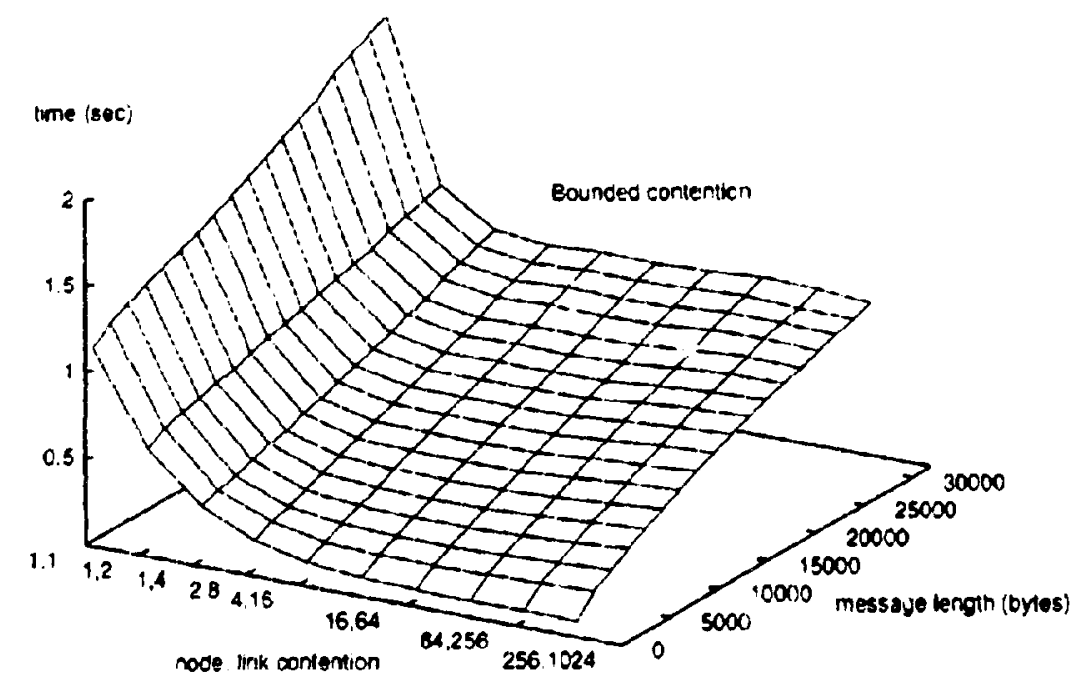

Figure 10: Performance of Bounded contention algorithm on a $16 \times 16$ Paragon. The najie algorithm fails to work on this mesh and the Bounded algorithm fails at contention (25fi. 1024) because of operating system limitations.

is initially much poorer than the naive algorithm but improves ve $z$ rapidly with increasing contention. The initial steep drop is due to the collapsing of the schedule. (which increases link contention but not node contention) anc to the large reduction in synchronization steps. As conterition increases, further improvernents are obtained because of reduction in synchronization and because of the corrcurrent opcration of the communicution processor. However the improvernent is arrested at node contention $=16$ when the decrease in synchronization steps can no longer offsct the overleead due to node and link contention. Aftes this point the time starts increasing.

The performance of the Bounder algorithm for $16 \times 16$ meshes is shown in Figure 10. The Paragon failed to execute the naive algorithm for this mesh size. This is ber ausie the operating system could not allocate enough resources to accommodate the 256 reccives required by the algerithm. The Bounded algorithm itself could not be be tested for thic mesh size for node contention $=2: 56$ for the same reason.

The relative performance of the two algorithms is clear in Figure 11 which shows contours that indicate the percentage imptovement of Bounded over naje. These contours show that improvements of greater than $25 \%$ are possible on $8 \times 3$ and $12 \times 12$ me:hes for inost rnessage sizes, provided the comertion level is chosen carefull: The contours help us pick the best contention level for a given message size.

To study our experimental results in greater detail we provide slices. at message

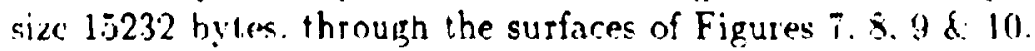

The solid curves in these figures whow the measured time to excrute Bounded con. tention complete exchange. This measured time is compared with ho predicted time. obtained by adding sychronization and communication time taken from I able 1. 


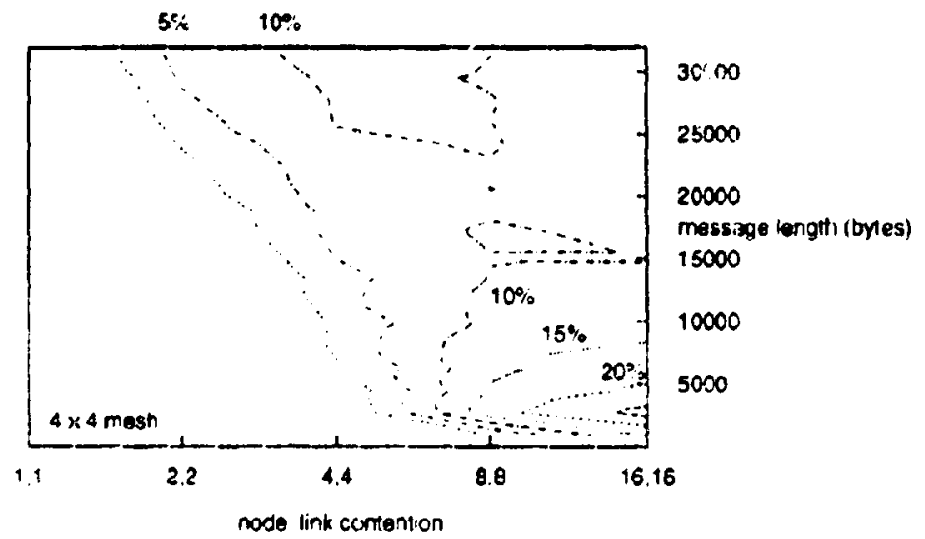

$152025 \%$
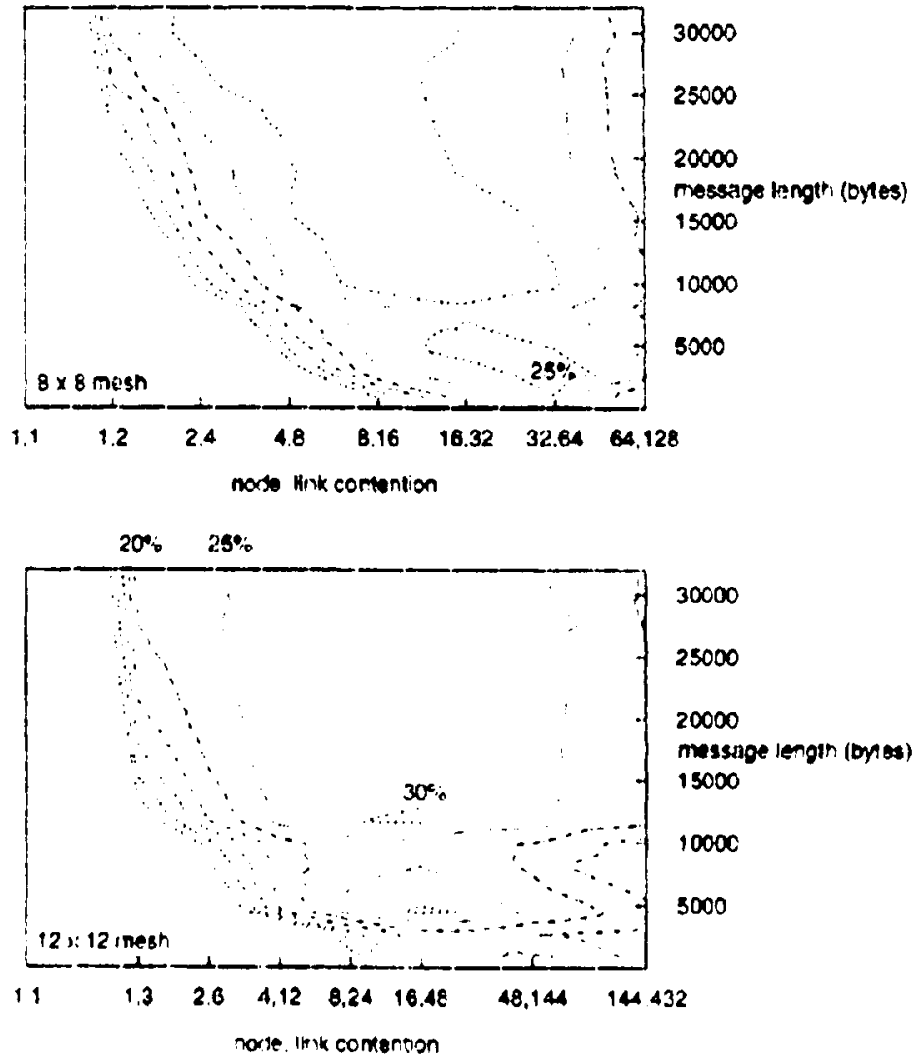

Figure 11: C'ontour pleis of percentuge improvement provided by Bounded contention algorithn over naive algorithn for $; \times 4,8 \times 8$ and $12 \times 12$ Paragon meshes. 


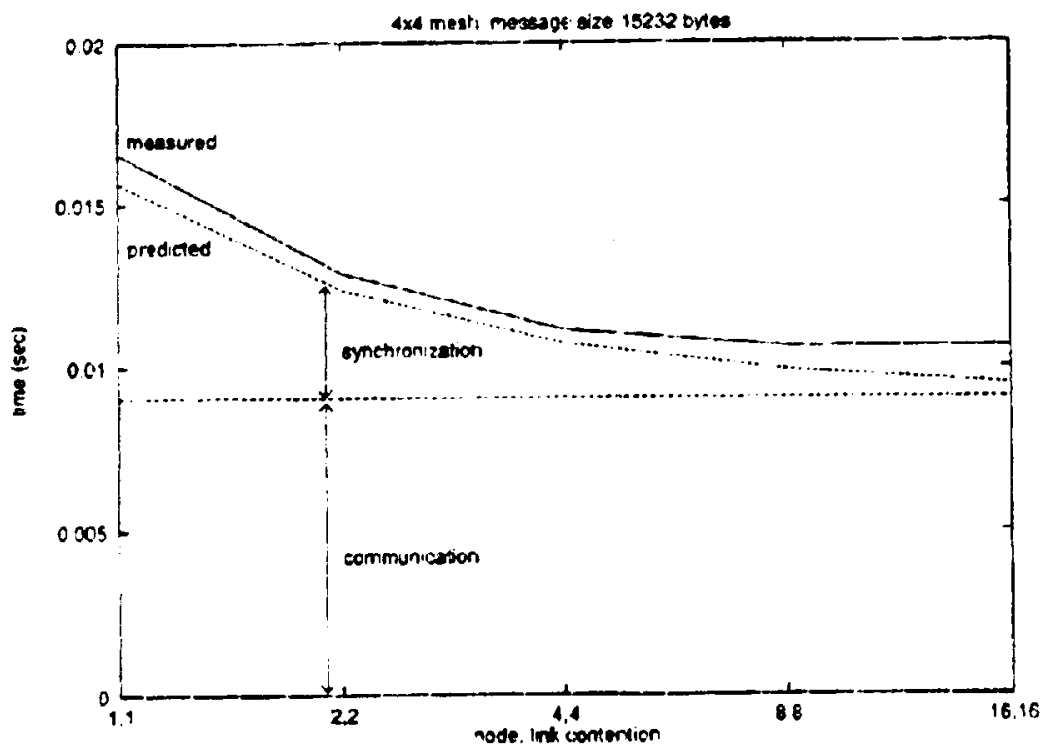

Figure 12: A slice through the surface for a $4 \times 4$ Paragon.

Figure 12 show's a slice through the surface for a $4 \times 4$ mesh (Figure i). Three asferts of this figure are noteworihy.

- The agreement between predicted and measured times is good.

- The communication time fraction of the total predicted time is const.unt. This is because in a $4 \times 4$ mesh scbedule there are no idle processors. Thus. evan when we increase perrnitted contention, the schedule cannol collapse because of the lack of "holes" in the permutations.

- The increase in performance comes about because of redurtion in synchronization overhead.

The slice of the $8 \times 8$ surface Figure 13 ) bring out several interesting issies. Io circumrent the difficulty of predicting performance we have interted upper and lower bounds for time to execute complete exchange in this and subsequent figures. The loxer bound gives the sum of communication and șnchronization times as given in. Table 1. Note that the cormmunication time is halved going from link content ion 1 to 2. This is because. as shown in Table 2. the number of communication steps drops from 128 to tit for at $8 \times 8$ mesh. Fince the lowey bound does not inclurde the overheads of node and link cortention, the measured time should not drop bolow this curve. 


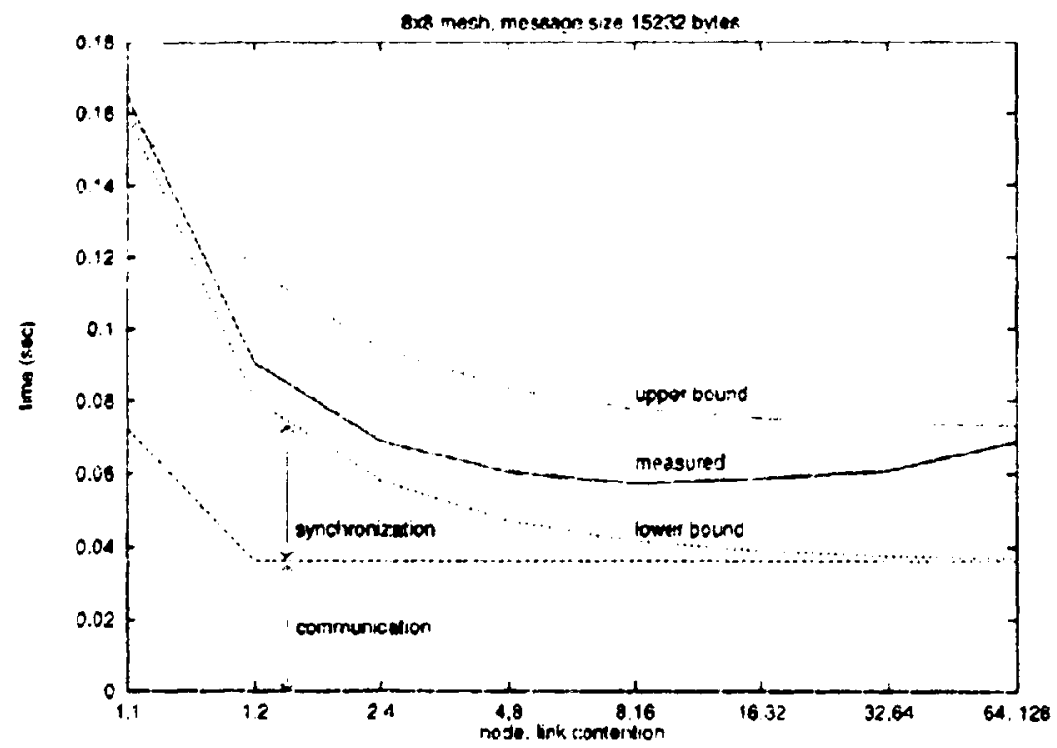

Figure 13: A silice through the surface for an $8 \times 8$ Paragon.

The Bounded contention algorithm increases permitted contention by deletıng barriers. This remores control over the launching of messages: a processor cin fire off the next message in its schedule without waiting for synchronization. Some messages, may be: launched along paths already in use, thereby increasing contention. The impact of this contention is very difficult to estimate because the communication palterns of the Bounded algorithm are complex anci their contention cannot be characterized simply.

The upper bound carre give: the sum of synchronization and communication times, assuming that all 128 message steps are executed serially. We would expect the measured times to lire between the two bounds. The closer the incasurcd timc is to the bower bound. the greater is the success of the Bounded approach. On the other hand, the measured curve would approach the upper bound when the contention overheads exceed the reduction in communication and synchronization time.

In Figure 13 we see that the measured time is close to the lower bound for link conemtion 1. 2 \& 4 . Beyond 4 the measured hime starts deviating significantly, reaching a mininum at link contention 16 . Similar comments apply to the slices for $12 \times 12$ and $16 \times 16$ meshes (Figures $14 \& 15)$. In the latier it is noteworthy that the measured time almost touches (but does not cross) the upper bound at contention (128.51?). (Rerall that this experiment conld not be rus for the last contention ralue of (256.1024) because of operating system limitationa.) This shows that onr algorithm is rolust in the sensie that the measured time remains hounded by the time to execute the individual communication steps. 


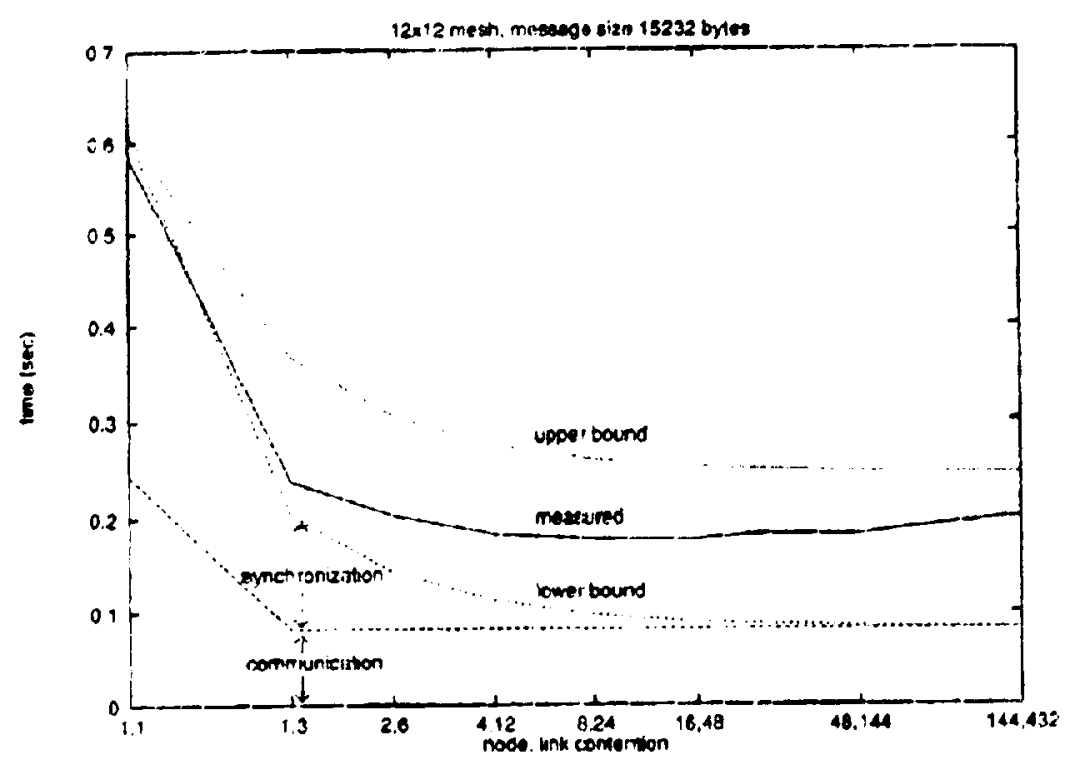

Figure 14: A slice through the surface for a $12 \times 12$ Paragon.

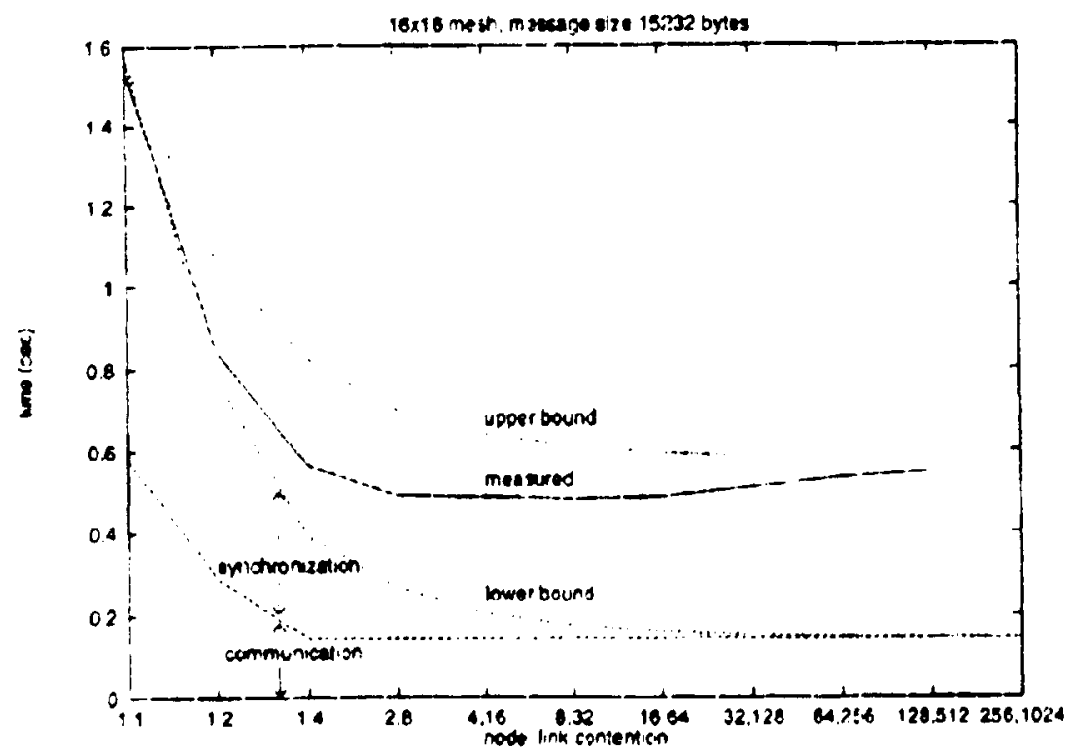

Figurc 15: A sibe through the surface for a $16: 16$ Paragon. 
Figures 13.14 and 15 show that a careful choice. .o. sntion levels is necessary to obtain the best performance. It is not enough to blindly remove all synchronization steps.

\section{Conclusions}

Complete exchange is an important communication requirement that is difficult to execute efficiently on meshes. We have developed a new Bounded contention algorithrn that takes advantage of the high performance communication mechanism on the Paragon to achieve good timings. 'The performance of this algorithm has been measured to be better than that of a naive algorithm that does not take network topology into account. Our experience appears to contractict the commonly held belief that topology does not have to the considered when designing parallel algorithms for modern parallel computer systems.

Our results are applicable to all meshes in which. like the Paragon. the rate at which data can be transmitted across the interconnect is higher than the rate at which data can be injected into the interconnect. The successor to the Intel Paragon is the ASCI Teratlop machine with a dual mesh interconnect [12]. This machine can take advantage of our results in an interesting fashion. Our algorithm essentially "slices" the complete exchange communication pattorn into a series of sub-patterns, each with a bounded contention. These sub-patterns can be alternately assigned to the twu meshes permitting us to take full advantage of the ASCI: newerful interconnect. These results are also applicable to 3 d meshes because Scott . Wasic algorithm can be extended to higher dimensions.

An interesting area of further research would be to conbine the Bounded algorithm which is optimal for large message sizes; with the multiphase algorithm (4) which has been shown to be applicable to the Paragon [5], and gives the best performance for srnall messiage sizes.

Perhaps the most crucial conclusion to be drawn from our experiments is the importance of synchronization time in determining the overall execution time of a communication step. Our results indicate that investment in an improved synchronization mechanism. perlaps relying on a network distinct. from the net work uscd for data comnurication. would yicld handsome dividesds in terms of improved communication performance.

\section{Acknowledgments}

We are grateful to. Wanuel Salas. Direct or ICASE. for his encouragement of this research. Discussions with Ton: Crockett. Panl Fischer. David Keyes. Pivush Mehrotra, John Van Resendale. Stown Sridel and Xian-lle Sun have been very valuable. 
Access to the supercomputers at Caltech was arranged by Paul Messina. We wish to thank him and his able staff: Walker Aumann, Bevan Bennett, Sharon Burnett. Mat thew Carle, Clark Chang. Shay Chinn, Alex Leung. Jan Lindheim, Heidj Lorenz-Wirzba, Julje Murphy, Mark L. Jejdengard. Gary Dell'Osso, Andrew Sun, and Elsa Villate, for their alacrity in answering out queries and for their patient toleranre of the numerous crashes we caused on their machines. Thanh Phung, $A$ Bessey and Ellen Deleganes of Intel helped us vith various problems on the Paragon.

\section{References}

[1] S. H. Bokhari and S. Berryman. Complete exchange on a circuit suitched mesh. In Proc. Scalable High Performance Computing Conf.. pages 300-306. 1.992.

(2) Shahid H. Bokhari. Communication overhead on the Intel Paragon. IBM SP2 and Meiko CS-2. ICASE Interim Report 28, IASA Contractor report 198211. September 1995. http://ww . lcase. odu/docs/hilites/index. interim.html.

[3] Shahid H. Bokhari. Communication overheads on the Intel iPSC.860 hypercube. IC.ASF. Interim Report 10, May 1990.

[1] Shahid H. Bokhari. Multiphase complete exchange: A theoretical analysis. IEFE Transactions ore Computers, 45(2):220-229, February 1996.

[j] Shahid H. Bokhari. Multiphase complete exchange on Paragon, SP2 and CS-2. IEEE Parallel and Diotr. uted Technology. 3(4):45; 53, Fall 1996.

[6] C.T. Ho and M. T. Raghunath. Efficient communication primitives on hypercubes. In Proc. 6th. Conf. Distributed 1/6mory Concurrent C'omputers. pages 390 39\%. 1991.

[7] S. Lennart Johnsson and Ching-ïien Ho. Optimurn broadcasting and personalized communication in hypercubes. IEEE' Trans. Computers, ( $-38(9): 1249-1268$. September 1989 .

[8] T. Schmiermund and S. R. Seidel. A communication model for the Intel iPSC/2. Technical Rreport (S.TK 9002. Dept. of Computer Science, Michigan Tech. Univ.. April 1990.

19; D. S. Scolt. Efficient all to all communication patterns in hypurcube and mesh topologiess. In Pros. cith. Conf. Distributed Me mory Conrument Computers, pages 3998-403. 1991.

[10] Haze] Shirley. Robert Reyrolds, and Steve R. Seidel. Communication on the Intel Paragon. Technical Report CS.TR-9.5-0i, Dept. of Computer Science. Michigan Tech. Univ.. July 17. 1995 .

(11) R. Take. A routing method for the all-tn-all busst on hypercube network. In Pror.

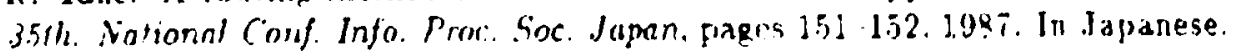

[12] Tom Thompson. The world's fastest compuler (for now). Bytc. 21(1):62. January. 1996. 


\begin{tabular}{|c|c|c|c|}
\hline \multicolumn{3}{|c|}{ REPORT DOC :JENTATION PAGE } & $\begin{array}{l}\text { Form Approwed } \\
\text { OMB No 070L } 0188\end{array}$ \\
\hline \multicolumn{4}{|c|}{ 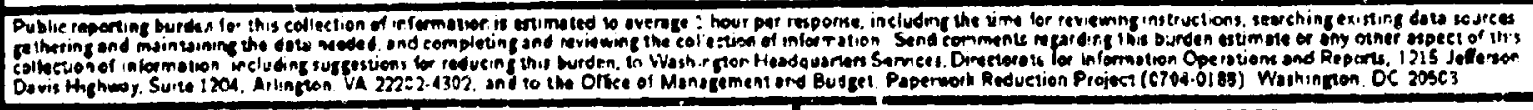 } \\
\hline \multicolumn{4}{|c|}{\begin{tabular}{|l|l|l|} 
1. AGENCY USE ONLY(Leave biank) & $\begin{array}{c}\text { 2. REPORT DATE } \\
\text { Aqgust } 1996\end{array}$ & $\begin{array}{l}\text { 3. REF ORT TYPE AND DATES COVERED } \\
\text { Contractor Report }\end{array}$ \\
\end{tabular}} \\
\hline \multicolumn{3}{|c|}{$\begin{array}{l}\text { 4. TITLE AND SUETITLE } \\
\text { BALA NCING CONT EYTION ANDSYNCHRONIZATION ON THE } \\
\text { INTEL PARAGO. }\end{array}$} & \multirow[t]{2}{*}{$\begin{array}{l}\text { 5. FUMDING NUMBERS } \\
\text { C NAS1-19480 } \\
\text { WT: } 505-90-52-01\end{array}$} \\
\hline \multicolumn{3}{|l|}{$\begin{array}{l}\text { 6. AUTHOR(S) } \\
\text { Shahid H. Bokhari } \\
\text { David M. Nicol }\end{array}$} & \\
\hline \multicolumn{3}{|c|}{$\begin{array}{l}\text { 7. PERfORMING ORGANIZATION MAME(S) ANO AODRESS(ES) } \\
\text { Institute for Computer Applications in Science and Engineering } \\
\text { Mail Stop } 132 \text { C. NASA I,angley Research Center } \\
\text { Hampton. VA } 23681-000.1\end{array}$} & $\begin{array}{l}\text { 6. PERFORMING ORGANIZATION } \\
\text { REPORT NUMBER } \\
\text { ICASE Report No. } 96-54\end{array}$ \\
\hline \multicolumn{3}{|c|}{$\begin{array}{l}\text { 9. SPONSORING/MONITORING AGENCY NAME(S) ANO ADORESS(ES) } \\
\text { National Aeronautics and Space Administration } \\
\text { Langley Reserrch Center } \\
\text { Hampton. VA } 236 \$ 1-000\end{array}$} & $\begin{array}{l}\text { 10. SPONSOAING/MONITOAING } \\
\text { AGENCY REPORT MUMBER } \\
\text { NASA CR-20159? } \\
\text { KCASEE HEPOIT TO. } 96.54\end{array}$ \\
\hline \multicolumn{4}{|c|}{$\begin{array}{l}\text { It. SUPPLEMEMTARY MOTES } \\
\text { Langley Terhnicial M.opitor: Dennis M. Bushne:l } \\
\text { Final Report } \\
\text { Submitted to IEEE Parallel \& Distributed Terhnology. }\end{array}$} \\
\hline \multicolumn{3}{|c|}{$\begin{array}{l}\text { 220. DISTRIBUTION/AVAILABILITY SYATRMENT } \\
\text { linclassified-Inlimited } \\
\text { Subject. Category } 60.61\end{array}$} & 12b. OISTRIBUTION CODE \\
\hline \multicolumn{4}{|c|}{ 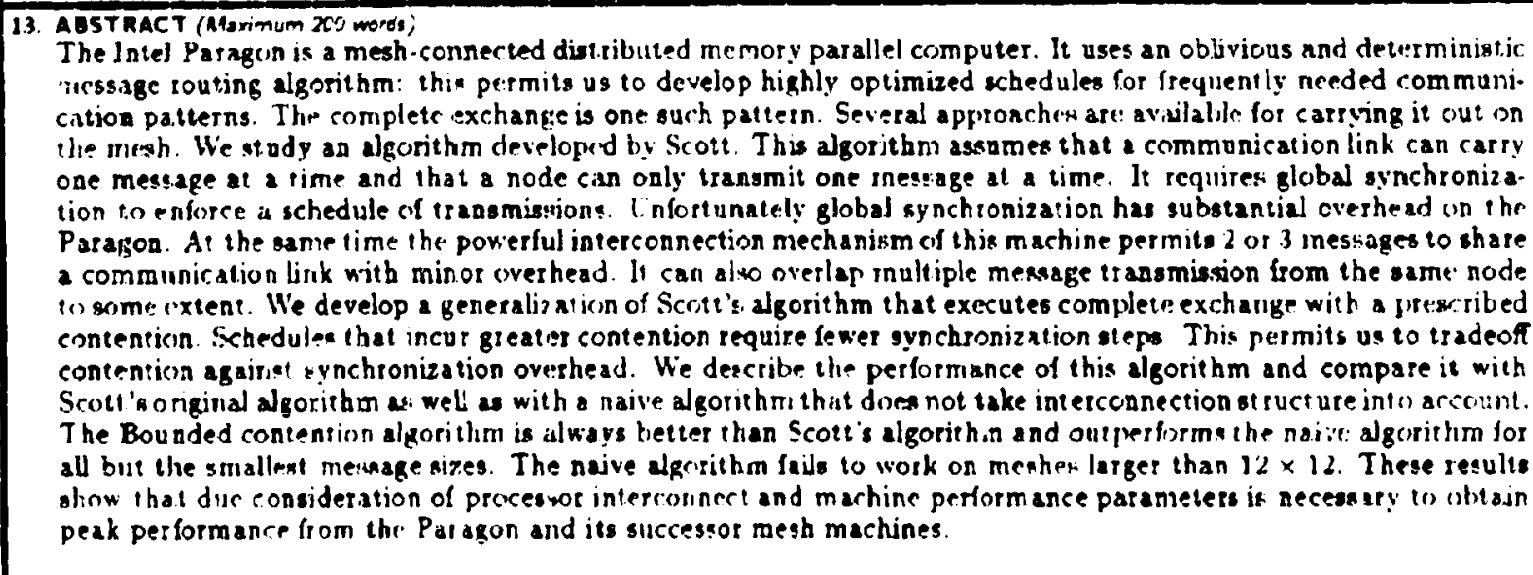 } \\
\hline \multirow{2}{*}{\multicolumn{3}{|c|}{ 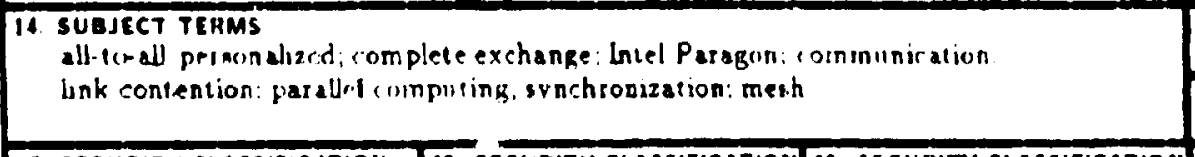 }} & $\begin{array}{l}\text { 15. NUM isER OR PAGES } \\
22\end{array}$ \\
\hline & & & $\begin{array}{c}\text { 16. PRICE CODE } \\
\text { AQ3 }\end{array}$ \\
\hline $\begin{array}{l}\text { 11. SECUAITY CLASSIFICATION } \\
\text { OF RLPORT } \\
\text { linclidesifiert }\end{array}$ & $\begin{array}{l}\text { 16. SECURITY CLASSIFICATION } \\
\text { OP THIS PAGE } \\
\text { UnClasaified }\end{array}$ & $\begin{array}{l}\text { 19. SICURITY CLNSSIFICATION } \\
\text { OR ABSTRACT }\end{array}$ & $\begin{array}{l}\text { 20. LGMITATION } \\
\text { OF ABSTRACT }\end{array}$ \\
\hline 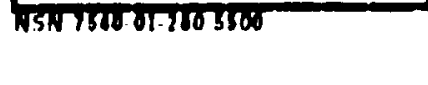 & & & 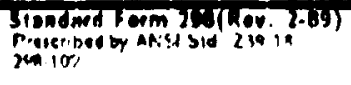 \\
\hline
\end{tabular}

